\title{
Eclipse retinopathy
}

\author{
S. P. DHIR, AMOD GUPTA, AND I. S. JAIN \\ From the Department of Ophthalmology, Postgraduate Institute of Medical Education \\ and Research, Chandigarh-160012, India
}

SUMmaRY Ten patients (13 eyes) suffered from varying degrees of eclipse retinopathy during a solar eclipse on 16 February 1980 . There was no correlation between severity of the fundus lesions and the visual acuity. In 8 of the 10 eyes available for follow-up $6 / 6$ or better visual acuity was seen. Early fluorescein studies revealed microleaks in 3 eyes ( 2 patients) and masking of choroidal fluorescence in 1 eye; however, 1 to 3 weeks later these eyes showed only faint window defects. It is postulated that in mild to moderate lesions there is a transient retinal capillary spasm, producing oedema in anterior retinal layers. Fluorescein angiography in such patients reveals no abnormality or only masking of choroidal fluorescence. However, severe cases develop micropunctures in the tight junctions of the pigment epithelium, leading to microleaks, which are sealed within a short period.

On 16 February 1980 a partial solar eclipse was observed over the Chandigarh area. Despite repeated warnings by the publicity media as to its harmful effects on the eyes, 30 patients who had watched it reported to the Eye Department of the Postgraduate Institute of Medical Education and Research. This study reports the results of clinical and early and late fluorescein angiographic studies on these patients.

\section{Material and methods}

A detailed examination of all the patients was carried out which included recording of duration of exposure, protective device used, if any, subjective symptoms, visual acuity, fundus examination, and refraction. Ten patients (13 eyes) were found to have clinical evidence of solar retinopathy. Fluorescein angiography was done in all the eyes showing clinical lesions and repeated again after an interval of 1 to 3 weeks.

\section{Results}

All the affected patients were males and between 11 and 40 years, mean $26 \cdot 2$ years (Table 1). Three patients reported within 24 hours of having watched the solar eclipse. Five presented within 4 days, 1 after a week, and 1 after 4 weeks.

Most of the patients (8) had gazed at the eclipse

Correspondence to Dr S. P. Dhir. momentarily ( 5 seconds or so). One patient (case 3 ) claimed to have watched the eclipse for almost 4 hours intermittently. Another patient (case 7) watched the eclipse about 20 times, every time for 20-30 seconds. No protective device was used by 6 patients, a pinhole was used by 2 , sunglasses by 1 , and a double layer of exposed photographic film by 1 patient.

Five patients presented for a mere check-up and had no complaints. Two complained of blurred vision, another 2 of positive scotomas, and 1 complained of mild itching only.

Seven patients had unilateral involvement and 3 bilateral. The initial and final visual acuity in the 13 affected eyes is shown in Table 2. At the time of presentation 3 eyes had a visual acuity of $6 / 6$ or better. Six eyes had visual acuity of $6 / 9$ and 2 each of $6 / 12$ and $6 / 18$. None of the involved eyes had visual acuity of less than 6/18. None of the eyes had any significant refractive error.

\section{FUNDUS PICTURE}

The fundus lesions could be grouped into mild, moderate, and severe. They were parafoveal in 4 eyes and perifoveal in 9. Mild lesions consisted of a dark brown granular lesion at the macula without any associated retinal oedema and was seen in 5 eyes. Moderate lesions were seen in 5 eyes and consisted of a reddish brown granular area surrounded by a grey ring of perifoveal retinal oedema. Severe lesions were seen as a greyish white patch indicative of severe retinal oedema or acute retinal 
Table 1 Clinical details

\begin{tabular}{|c|c|c|c|c|c|c|c|c|c|c|c|}
\hline \multirow{2}{*}{ Case } & \multirow{2}{*}{$\begin{array}{l}\text { Age } \\
(y r)\end{array}$} & \multirow{2}{*}{$\operatorname{Sex}$} & \multirow{2}{*}{ Occupation } & \multirow{2}{*}{$\begin{array}{l}\text { Eye } \\
\text { involved }\end{array}$} & \multirow{2}{*}{$\begin{array}{l}\text { Protective } \\
\text { device/aid }\end{array}$} & \multirow{2}{*}{$\begin{array}{l}\text { Fundus } \\
\text { lesion } \\
\text { grade }\end{array}$} & \multicolumn{2}{|c|}{ Visual acuity } & \multicolumn{2}{|c|}{ Fluorescein angiography } & \multirow{2}{*}{ Remarks } \\
\hline & & & & & & & Initial & Final & Initial & $\begin{array}{l}\text { Late } 3 \\
\text { weeks }\end{array}$ & \\
\hline 1 & 32 & $\mathbf{M}$ & Engineer & $\mathbf{R}$ & Pinhole & Mild & $6 / 9$ & $6 / 6$ & NAD & NAD & - \\
\hline 2 & 17 & $\mathbf{M}$ & Student & $\mathbf{R}$ & Nil & Mod. & $6 / 6$ & $6 / 5$ & $\begin{array}{l}\text { Parafoveal } \\
\text { leak }\end{array}$ & $\begin{array}{l}\text { Linear } \\
\text { window } \\
\text { defect }\end{array}$ & $\begin{array}{l}\text { Developed pseudolamellar } \\
\text { macular hole at } 3 \text { weeks which } \\
\text { disappeared at } 3 \text { months }\end{array}$ \\
\hline 3 & 25 & $\mathbf{M}$ & Driver & Both & Nil & Severe & $6 / 9,6 / 9$ & $6 / 6,6 / 6$ & $\begin{array}{l}\text { Parafoveal } \\
\text { microleak } \\
\text { BE }\end{array}$ & $\begin{array}{l}\text { Window } \\
\text { defect BE }\end{array}$ & $\begin{array}{l}\text { Parafoveal macular hole } \\
\text { BE at fourth day }\end{array}$ \\
\hline 4 & 30 & $\mathbf{M}$ & Peon & Both & Sunglasses & Mod. & $6 / 9,6 / 9$ & $6 / 9,6 / 18$ & $\begin{array}{l}\text { Window } \\
\text { defect BE }\end{array}$ & $\begin{array}{l}\text { Window } \\
\text { defect } B E\end{array}$ & $\begin{array}{l}\text { True macular hole BE } \\
\text { at } 3 \text { weeks }\end{array}$ \\
\hline 5 & 40 & $\mathbf{M}$ & Administ. & $\mathbf{L}$ & $\begin{array}{l}\text { Double layer } \\
\text { exp. film }\end{array}$ & Severe & $6 / 9$ & $6 / 6$ & NAD & NAD & Parafoveal pseudohole \\
\hline 6 & 11 & $\mathbf{M}$ & Student & $\mathbf{R}$ & Nil & Mod. & $6 / 18$ & $6 / 6$ & $\begin{array}{l}\text { Masking } \\
\text { choroid } \\
\text { fluorescence }\end{array}$ & NAD & - \\
\hline 7 & 23 & $\mathbf{M}$ & Student & $\mathbf{R}$ & Pinhole & Mod. & $6 / 12$ & $*$ & $*$ & * & No hole formation \\
\hline 8 & 32 & $\mathbf{M}$ & Clerk & $\mathbf{R}$ & Nil & Mild & $6 / 6$ & $6 / 5$ & NAD & NAD & - \\
\hline 9 & 32 & $\mathbf{M}$ & Labourer & Both & Nil & Mild & $6 / 12,6 / 18$ & $*$ & $*$ & $*$ & $*$ \\
\hline 10 & 22 & $\mathbf{M}$ & Student & $\mathbf{R}$ & Nil & Mild & $6 / 5$ & $6 / 5$ & NAD & NAD & - \\
\hline
\end{tabular}

*No follow-up available ( 3 eyes). BE $=$ Both eyes. NAD = Nothing abnormal detected.

necrosis. This was seen in 3 eyes. These lesions were parafoveal in location in all the eyes. Irrespective of the severity of the lesion a bright foveal reflex could be seen in 9 eyes.

\section{FLUORESCEIN ANGIOGRAPHY}

All 10 patients (13 eyes) were studied by fluorescein angiography. Six patients (8 eyes) did not show any fluorescein angiographic abnormality. One patient showed a transmission defect in the macular area (case 4). Masking of choroidal fluorescence was seen in the macular area in case 6 (Figs. 1a and b). Another 2 patients ( 3 eyes) showed microleaks in the parafoveal area (Figs. 2a and b).

Table 2 Initial and final visual acuity

\begin{tabular}{lll}
\hline $\begin{array}{l}\text { Visual } \\
\text { acuity }\end{array}$ & $\begin{array}{l}\text { Initial } \\
\text { (no. of eyes) }\end{array}$ & $\begin{array}{l}\text { Final } \\
\text { (no. of eyes) }\end{array}$ \\
\hline $6 / 5-6 / 6$ & 3 & 8 \\
$6 / 9$ & 6 & 1 \\
$6 / 12$ & 2 & - \\
$6 / 18$ & 2 & 1 \\
$6 / 24$ & - & - \\
$6 / 36$ & - & - \\
$6 / 60$ & - & - \\
Total & 13 & $10^{*}$ \\
\hline
\end{tabular}

*In 3 ejes no follow-up available.
FOLLOW-UP

Eight patients (10 eyes) were available for follow-up. Three eyes which showed initial mild lesion and 1 eye with a moderate lesion cleared within 3 weeks and regained visual acuity of $6 / 6$ or better. Three of the 5 eyes with moderate lesions and all 3 eyes with severe lesions developed foveomacular holes within 4 days to 3 weeks. There was clumping of fine pigment round the holes. Four of these eyes also showed visual improvement to $6 / 6$ or better. In 1 patient (case 2) the macular hole appearance disappeared in about 3 months time.

Follow-up fluorescein studies done 1 to 3 weeks later revealed only faint window defects in 3 patients. No leakage of dye could be demonstrated at this stage.

\section{Comments}

The clinical picture of eclipse retinopathy is well described. ${ }^{1-4}$ Usually there is bilateral involvement. In unilateral cases the right eye, as the dominant eye, is affected more often. ${ }^{4}$ Young people, because of their adventurous nature (exemplified by our cases 3 and 7) and transparent crystalline lenses, are at a greater risk of developing solar burns than older. Mostly the affected patients are emmetropes.

Mild to moderately severe lesions were perifoveal ( 9 out of 10 eyes), whereas all the severe lesions were 

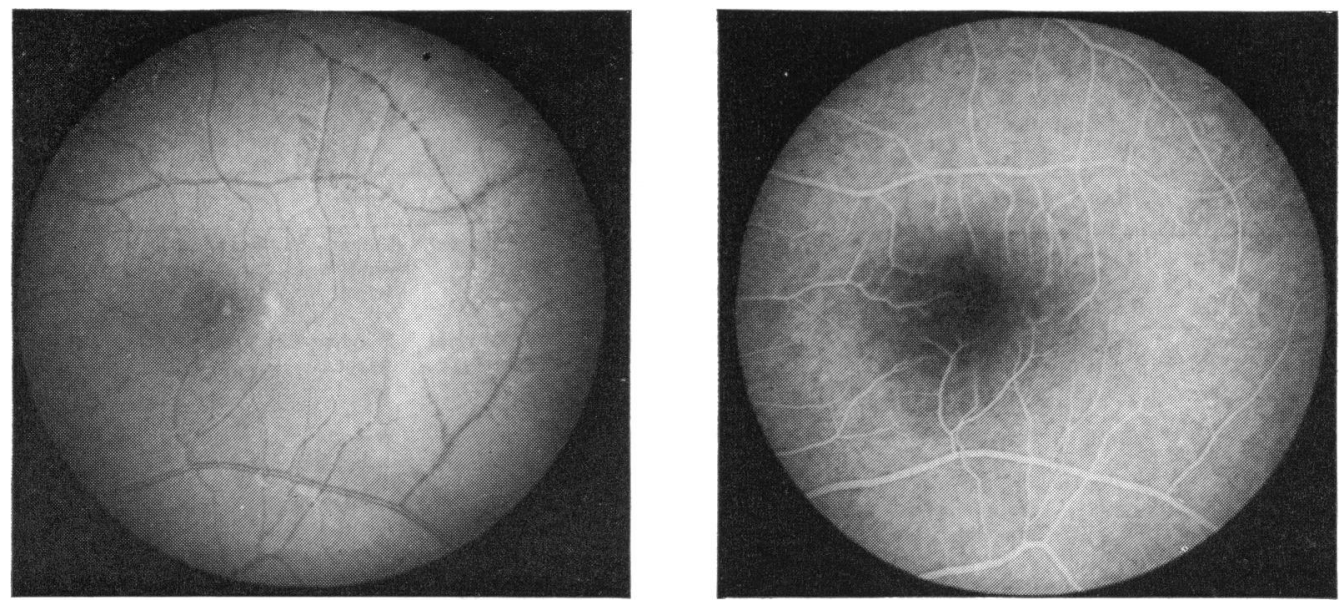

Fig. 1 Case 6. Moderate eclipse burn. (Left) Fundus picture shows macular oedema. (Right) Fluorescein angiography shows masking of choroidal fluorescence in the early arterial phase corresponding to the macular oedema.
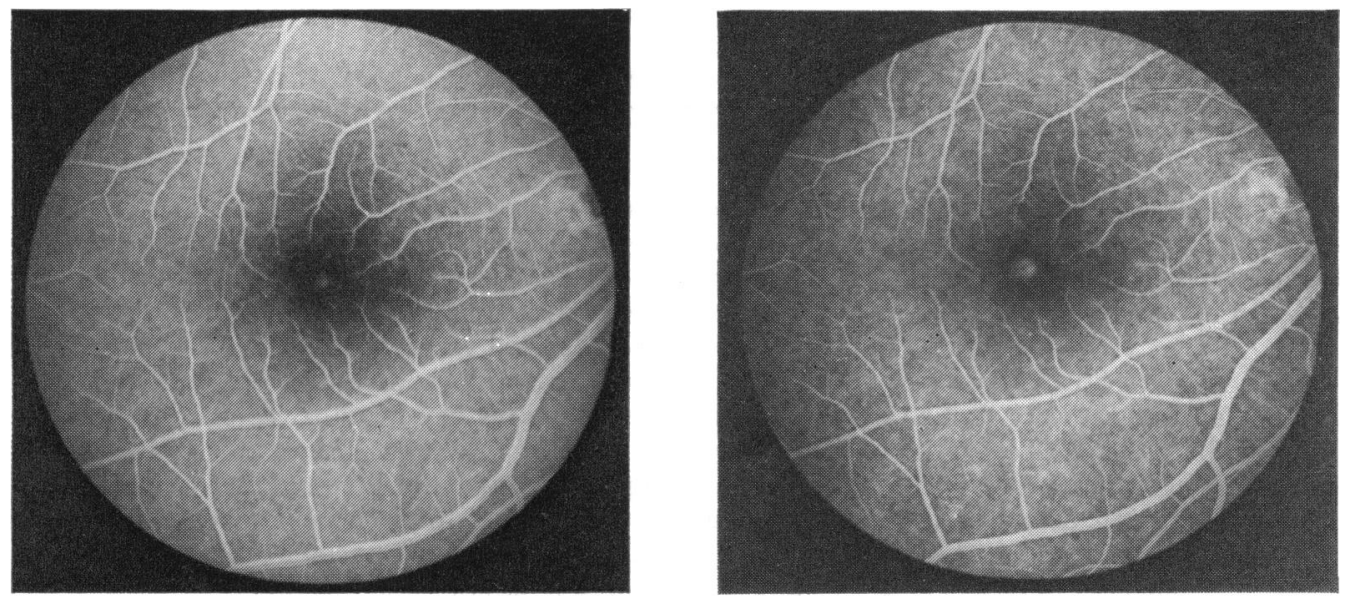

Fig. 2 Case 3. Severe eclipse burn. (Left) Early fluorescein angiogram shows parafoveal microleak. (Right) Late picture shows increased fuorescein staining.

parafoveal. Thus it appears that the fovea is spared from damage by lack of foveal fixation, which may allow the patient to gaze at the eclipse for longer duration and consequently produce severe parafoveal burns.

We did not find any correlation between visual acuity and the severity of the lesion. In a patient (case 3) who claimed to have gazed at the sun for almost 4 hours the fovea was spared, although a severe degree of parafoveal burn was produced in both eyes. Visual acuity surprisingly was $6 / 6$ in both eyes.

Fluorescein angiography helped to classify the pathogenesis of the retinal lesions. Eight eyes, despite a well developed ophthalmoscopic lesion did not show any fluorescein angiographic defect. No leakage of the dye from the retinal capillaries or choroid was seen, nor did pigment epithelium show any masking or transmission defect. It appears that the lesion in these eyes was situated in the anterior retinal layers and was due to a transient retinal capillary spasm. Three eyes which showed microleaks had micropunctures at the level of the tight junctions of the pigment epithelial cells. They disappeared in a week, indicating a fast recovery. They represent a severe degree of exposure. Masking 


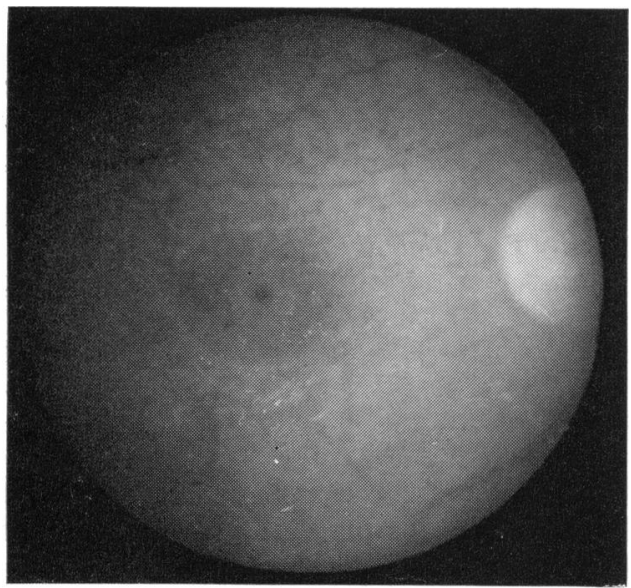

Fig. 3 Case 2. Moderate eclipse retinopathy.

Pseudolamellar foveomacular hole seen 3 weeks after eclipse burn. This lesion completely resolved when seen after 3 months.

of choroidal fluorescence by oedema or exudation represents an intermediate lesion. A faint transmission defect may be seen in the late stage due to depigmentation of the pigment epithelial cells (case 4). Reports on fluorescein angiography in eclipse retinopathy are still inconclusive. ${ }^{5}$ Localised leaks have been reported occasionally. ${ }^{6}$ ?

In the majority of patients who suffer moderate to severe burns the lesion finally resolves into a foveomacular hole surrounded by fine pigment clumps. Two types of hole formation may be seen. Pseudolamellar foveomacular holes are formed by acute pigment epithelial cell necrosis by absorption and release of heat energy in this layer, with subsequent formation of pigment epithelial cysts. The inner retinal layers are intact, and this condition gives a hole-like appearance due to visibility of choroidal vessels through the cyst. ${ }^{8}$ This phenomenon was observed in case 2 , in which at 3 weeks a hole-like lesion developed at the macula (Fig. 3). At this stage fluorescein angiography showed a linear window defect. In about 3 months' time the hole-like lesion completely disappeared, and no abnormality could be seen on fluorescein angiographic study. True lamellar holes, however, may develop if the inner retinal layers also undergo necrosis (Fig. 4).

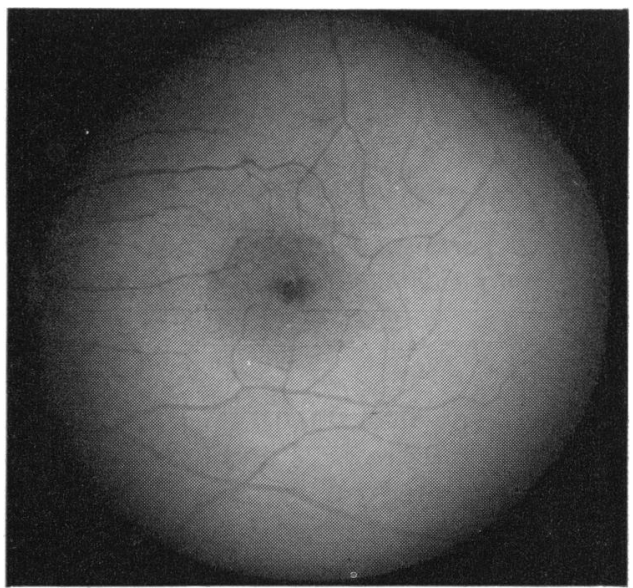

Fig. 4 Moderate eclipse retinopathy both eyes. True lamellar macular hole developed at 3 weeks. Visual acuity in the left eye deteriorated from $6 / 9$ to $6 / 18$.

In contrast to previous reports ${ }^{9}$ the final visual prognosis was excellent. Eight out of the 10 eyes available for follow-up recovered $6 / 6$ or better visual acuity within 3 months of the eclipse burn, most of them having recovered within a period of 3 weeks. Late visual deterioration by 2 lines occurred in a patient who developed a true lamellar macular hole. But of the 3 other patients who developed pseudoholes at the macula none showed visual deterioration.

\section{References}

1 Rosen E. Solar retinitis. Br J Ophthalmol 1948; 32: 23-34.

2 Das T, Nirankari MS, Chaddah MR. Solar chorioretinal burn. Am J Ophthalmol 1956; 41: 1048-53.

3 Penner R, McNair JN. Eclipse blindness. Am J Ophthalmo $1966 ; 61: 1452-7$.

4 Duke-Elder S, MacFaul PA. System of Ophthalmology. London: Kimpton, 1972: 14 (2): 883-93.

5 Wergeland FL, Brenner EH. Solar retinopathy and foveomacular retinitis. Ann Ophthalmol 1975; 7: 495-503.

6 Zweng HC, Little HL, Peabody RR. Laser Photocoagulation and Retinal Angiography. St Louis: Mosby, 1969: 226.

7 Freedman J, Gombos GM. Fluorescein fundus angiography in self-induced solar retinopathy: a case report. Can J Ophthalmol 1971; 6: 124.

8 Ewald RA, Ritchey CL. Sun gazing as the cause of foveomacular retinitis. Am J Ophthalmol 1970; 70: 491-7.

9 MacFaul PA. Visual prognosis after solar retinopathy. Br J Ophthalmol 1969; 53: 534-41. 